\title{
Knowledge Level of University Students on Food Additives and their Perceptions Regarding Food Safety
}

\author{
Gokce $\mathrm{A}^{1}$, Bozkir $\mathrm{C}^{2}$, Seyitoglu $\mathrm{CD}^{* 1}$, Pehlivan $\mathrm{E}^{1}$ and Ozer $\mathrm{A}^{1}$ \\ ${ }^{1}$ Inonu University Medicine Faculty, Department of Public Health, Malatya, Turkey \\ ${ }^{2}$ Namik Kemal University, Schools of Health, Department of Nutrition and Dietetics, Tekirdağ, Turkey
}

*Corresponding author: Seyitoglu CD, Inonu University Medicine Faculty, Department of Public Health, Malatya, Turkey, Tel: 505648 9605, E-mail: drduygucelik@hotmail.com

\author{
Citation: Gokce A, Bozkir C, Seyitoglu CD, Pehlivan E, Ozer A (2018) Knowledge Level of University \\ Students on Food Additives and their Perceptions Regarding Food Safety. J Case Rep Stud 6(6): 604.
} doi: $10.15744 / 2348-9820.6 .604$

Received Date: August 27, 2018 Accepted Date: December 29, 2018 Published Date: December 31, 2018

\begin{abstract}
We aimed to assess the level of knowledge regarding food additives among medical and engineering students. This cross-sectional descriptive study included students from Inonu University Medicine and Engineering Faculty. The sample size was calculated considering the prevalence rate of food additive knowledge as $22.3 \%$, with a $95 \%$ confidence interval, $80 \%$ power and 918 individuals. A questionnaire was used to collect the socio-demographic characteristics of the students and their knowledge regarding food additives. Scores for knowledge regarding food additives were created; eight questions were posed to the students, and each known correct answer was given a score of 1. Pearson's chi-square test, Mann-Whitney U test and Kruskal-Wallis test were used for data analysis.Mean age of the students was $21.74 \pm 2.56$ years, and $51.7 \%$ of them were males. Knowledge level regarding the definition of food additives was not different between genders ( $p>0.05)$. Medical students had significantly higher knowledge levels $(92.2 \%)$ about the definition of food additives compared to those of engineering students $(80.4 \%)(\mathrm{p}<0.05)$. More males $(52.8 \%)$ than females $(49.3 \%)$ and more medical students (51.6\%) than engineering students (50.7\%) stated a significantly higher rate of daily consumption of processed foods containing additives $(\mathrm{p}<0.05)$. The median scores of knowledge regarding food additives were not significantly different between gender and faculty $(\mathrm{p}>0.05)$.The present study demonstrated that the rate of the participants who knew the definition of food additives as well as those who perceived food additives to be unsafe were high. Although the knowledge levels on FAs of the students were high in general, it was observed that the frequency of food consumed daily was high This suggests that further research and effective interventions are required to ensure that knowledge turns into behaviour.
\end{abstract}

Keywords: Knowledge; Students; Food Additives

\section{Introduction}

Food additives (FA) are substances that are not consumed as food and do not function as a typical raw material in nutriments, which do or do not have a nutritional value and are used to preserve the flavor, smell, appearance, structure and other features of food, and they are added deliberately for a technological objective in the course of production, processing, preparation, packaging and transportation [1,2]. The European Food Safety Authority defines food additives as "substances added intentionally to foodstuffs to perform certain technological functions, for example to color, to sweeten or to help preserve foods" [3]. Due to the changing living conditions in the 21st century, production and consumption of food underwent a transformation which in turn introduced new dietary styles. In consequence, utilization of food additives has also extended owing to the ever-developing technology as well as the changing domestic and professional life in the society.

Food additives can be classified into 4 different categories by the intended purpose. These include preservatives that prolong the shelf life of food by preserving quality (preservatives), food additives that enhance the structure, preparation and cooking properties, food additives that enhance flavor and color (artificial sweeteners and flavor enhancers), and food additives that preserve and enhance the nutritional value $[4,5]$.

Historically, use of food coloring dates back to ancient Egypt as early as $3500 \mathrm{BC}$, and salt had been used to preserve meat and meat products around 3000 BC. In addition to salting, fumigation was used as a food preservation method around 900 BC. In the middle ages, along with salting and fumigation, nitrate was added to meat in order to prevent botulism and it was noticed that the color of meat looked healthier with use of nitrate [6]. In other words, various methods have been utilized for centuries to preserve food in order to meet the demand for nutrition, which is essential for the existence of human beings. The change in the food consumption has introduced food safety and safe food concepts. The concept of food safety can be explained in different 
terms. It can be partially described as practices that prevent food-borne illnesses [7]. In a broader sense, food safety refers to preservation of nutritional value while preventing the potential of food-borne diseases that may be caused by the new products occurring during consumption, along with biochemical and microbiological safety of food [8]. Additionally, it describes the level of confidence in individuals regarding the production, consumption or distribution process against foodborne illnesses and health hazards depending on the use of the specific food [9].

In Turkey, Turkish Food Codex was published in November 16th, 1997, regarding the utilization of food additives. According to the legislation, 297 food additives were permitted for use in specified amounts [10]. The regulation also designated the specific quantities of different substances that are permitted to be added to specific foods. Relevant departments of the Ministry of Food, Agriculture and Livestock and the Ministry of Health audit manufactures whether the productions are in compliance with the codex, and authorize companies that conform to the regulations. In addition, food additives undergo long-standing and detailed safety tests in the laboratories. The results of these tests are approved by the international organizations in which Turkey is a member, the Joint FAO/WHO Expert Committee on Food Additives (JECFA) that is collectively established by the World Health Organization (WHO) and the Food and Agriculture Organization (FAO), Scientific Committee on Food (SCF) providing advice to European Commission, and Food and Drug Administration, specific amounts of each additive are determined in a particular food [4]. All food additives have an internationally acclaimed number based on the International Numbering System for Food Additives (INS). Food additives that are permitted for use within the European Union are named with a prefix of $\mathrm{E}$ that refers to "Europe" $[11,12]$. It is obligatory to specify the different functions of food additives (preservative, antioxidant, acidity, acidity regulators etc.) along with the name and/or specified E-code on food labels [4].

Food additives can either be natural or artificial $[13,14]$. Food additives to be used are selected according to the intended purpose. Food additives are not only used in the production of convenience foods. They can be added to all kinds of processed food that are offered for consumption. The use of food additives is indispensable for healthy storage of food and preservation of flavor [13]. Use of food additives in quantities that are in compliance with the legal standards in the food industry minimizes the risk. However, both the food manufacturer and the consumer bear important responsibilities in this sense. The producer should gain the confidence of the society by conforming to the regulations, and the consumer should perform their own control for their health rather than handing the control process down solely to governmental mechanisms.

The aim of the present study is to investigate the knowledge level of university students studying in the Faculty of Medicine and Faculty of Engineering at Inonu University on food additives, and their perceptions on food safety.

\section{Methods}

\section{Study Design}

The present study is designed as a descriptive cross-sectional study. Written approval of Inonu University Ethics Committee was obtained. The study included the students from the Faculty of Medicine and Faculty of Engineering at Inonu University who agreed to participate in the study in April 2016. The sample size was determined by the responses students gave to the question "Do you think food additives that are permitted by the government are healthy"; and it was calculated to be 459 with a 95\% confidence interval and $80 \%$ power [9]. 475 students from the Faculty of Medicine and 448 students from the Faculty of Engineering participated in the study. The study utilized simple random sampling method.

\section{Materials}

The students were asked to complete a questionnaire consisting of 33 questions created based on the literature review. The first part of the questionnaire was composed of questions regarding sociodemographic characteristics, whereas the second part was composed of questions on students' knowledge and perception about food additives and food safety. There were 8 questions investigating students' knowledge on food additives. The correct answer to each question was scored as 1 point. It was obtained "food additives knowledge score" by summing up these points. The independent variables of the study consisted of sociodemographic characteristics such as age, sex, marital status, and the faculty and income status, whereas dependent variables consisted of the scores obtained from the questions about students' level of knowledge on food additives.

\section{Analysis}

The statistical analysis was performed using SPSS (version 22.0) package program. Kolmogorov Smirnov test revealed that the knowledge score on food additives was not normally distributed $(p<0.05)$. In the statistical comparison between the groups Pearson chi-square, Mann-Whitney U, Kruskal Wallis test were used; and in the post hoc test, Bonferroni correction was applied and Mann-Whitney $\mathrm{U}$ test was conducted. A p value of $<0.05$ was considered to be statistically significant.

\section{Results}

\section{Table 1}

The average age of 923 students who participated in the study was $21.74 \pm 2.56$ years; $48,3 \%$ of the participants were female and 
$51,7 \%$ were male. The ratio of students studying in the Faculty of Medicine was 51, 5\%, whereas the ratio of students studying in the Faculty of Engineering was 48, 5\%. 32.7\% of the students were in the 18-20 age group, 49.52\% were in the $21-23$ age group, and $17,8 \%$ were above 24 years of age. $86.3 \%$ of the participants were resided in the city center, whereas $13,7 \%$ have resided in counties or villages (Table 1).

\begin{tabular}{|c|c|c|}
\hline & n & \% \\
\hline Gender & & \\
\hline Female & 446 & 48.3 \\
\hline Male & 477 & 51.7 \\
\hline Age & & \\
\hline $18-20$ age & 302 & 32.7 \\
\hline 21 -23 age & 457 & 49.5 \\
\hline 24 age $\leq$ & 164 & 17.8 \\
\hline Faculty & & \\
\hline Medicine Faculty & 475 & 51.5 \\
\hline Engineering Faculty & 448 & 48.5 \\
\hline Place of Residence & & \\
\hline City Center & 797 & 86.3 \\
\hline Counties/Village & 126 & 13.7 \\
\hline Total & 923 & 100 \\
\hline
\end{tabular}

Table 1: Sociodemographic Characteristics of Students Attending the Survey

\section{Table 2}

Table 2 presents sociodemographic characteristics of the students according to the level of knowledge on FA. As shown in the table, $85 \%$ of female students and $87,8 \%$ of male students knew the definition of FA ( $\mathrm{p}>0.05)$. The rate of medical students who were aware of the definition of FA $(92,2 \%)$ was significantly higher than the rate of engineering students who were aware of the definition of FA $(80,4 \%)(\mathrm{p}<0.05) .86 .4 \%$ of the students in the $18-20$ age group, $85,1 \%$ of the students in the $21-23$ age group, and $90,2 \%$ of the students aged above 24 years accurately were aware of the accurate definition of FA, and the difference between the groups was not statistically significant ( $\mathrm{p}>0.05$ ). 87,3\% of the students residing in the city center, and $87,3 \%$ of those residing in counties or villages were aware of the definition of FA $(\mathrm{p}>0.05)$.

\begin{tabular}{|c|c|c|c|c|}
\hline & Knowing $\mathbf{n}(\%)^{1}$ & Unknowing $\mathbf{n}(\%)^{1}$ & Total $\mathbf{n}(\%)^{2}$ & $\mathbf{p}$ \\
\hline \multicolumn{5}{|l|}{ Gender } \\
\hline Female & $379(85.0)$ & $67(15.0)$ & $446(48.3)$ & 0.204 \\
\hline Male & $419(87.8)$ & $58(12.2)$ & $477(51.7)$ & \\
\hline \multicolumn{5}{|l|}{ Faculty } \\
\hline Medicine Faculty & $438(92.2)$ & $37(7.8)$ & $475(51.5)$ & 0.001 \\
\hline Engineering Faculty & $360(80.4)$ & $88(19.6)$ & $448(48.5)$ & \\
\hline \multicolumn{5}{|l|}{ Age } \\
\hline $18-20$ age & $261(86.4)$ & $41(13.6)$ & $302(32.7)$ & \\
\hline $21-23$ age & $389(85.1)$ & $68(14.9)$ & $457(49.5)$ & 0.258 \\
\hline 24 age $\leq$ & $148(90.2)$ & $16(9.8)$ & $164(17.8)$ & \\
\hline \multicolumn{5}{|l|}{ Place of Residence } \\
\hline City Center & $696(87.3)$ & $101(12.7)$ & $797(86.3)$ & 0.52 \\
\hline Counties/Village & $102(81.0)$ & $24(19.0)$ & $126(13.7)$ & \\
\hline
\end{tabular}

\section{Table 3}

Packaged cakes, cookies and chocolate $(67,9 \%)$, packaged milk and dairy products $(65,1 \%)$, chicken and chicken products $(60$, $5 \%)$, bottled water $(60,5 \%)$ were the most commonly consumed processed foods among students. Canned goods (23, 5\%), and salami, pastrami and Turkish sausage $(34,3 \%)$ were the least preferred processed goods (Table 3 ). Almost half of the students consumed processed foods daily, 32, 8\% consumed 2-3 times a week, 11,2\% consumed once a week, whereas 1,4\% never consumed (Table 3). 


\begin{tabular}{|c|c|c|}
\hline Used Processed Foods & $\mathbf{n}$ & $\mathbf{\%}$ \\
\hline Dondurulmuş besinler & 350 & 37.9 \\
\hline Packaged milk and dairy products & 601 & 65.1 \\
\hline Turkish sausage,salami and pastrami & 317 & 34.3 \\
\hline Chicken and chicken products & 558 & 60.5 \\
\hline Bottled water & 558 & 60.5 \\
\hline Canned goods & 217 & 23.5 \\
\hline Packaged cakes, cookies, chocolate etc. & 627 & 67.9 \\
\hline Frequency of use & & \\
\hline Everyday & 472 & 51.1 \\
\hline 2-3 times a week & 303 & 32.8 \\
\hline Once a week & 103 & 11.2 \\
\hline Once a month & 29 & 3.1 \\
\hline Once every three months & 3 & 0.3 \\
\hline Never & 13 & 1.4 \\
\hline
\end{tabular}

Table 3: Processed Goods Used by Students Participating in the Survey and Usage Duty

\section{Table 4}

Table 4 presents the distribution of students' perceptions on the safety of processed foods that are permitted for sale by the Ministry of Food, Agriculture and Livestock with respect to their sociodemographic characteristics. $29.8 \%$ of the female students, $23,5 \%$ of the male students, $25,8 \%$ of the students residing in the city, and $31 \%$ of the students residing in counties and villages perceived FAs to be safe ( $p>0,05) .15 .2 \%$ of medical students and 38,6\% of engineering students perceived FAs to be safe; and the difference was statistically significant ( $\mathrm{p}<0.05) .28,8 \%$ of the students in the $18-20$ age group, $28 \%$ of the students in the $21-23$ age group, and $18,3 \%$ of students aged above 24 years perceived FAs to be safe, and the rate of students aged above 24 years who perceived FAs to be safe was significantly higher $(\mathrm{p}<0.05)$ (Table 4$)$.

\begin{tabular}{|c|c|c|c|c|}
\hline & Safe $\mathbf{n}(\%)^{\mathbf{1}}$ & Not safe $\mathbf{n}(\%)^{\mathbf{1}}$ & Total $\mathbf{n}(\%)^{\mathbf{2}}$ & $\mathbf{p}$ \\
\hline Gender & & & & \\
\hline Female & $133(29.8)$ & $313(70.2)$ & $446(48.3)$ & 0.18 \\
\hline Male & $112(23.5)$ & $365(76.5)$ & $447(51.7)$ & \\
\hline Faculty & & & & \\
\hline Medicine Faculty & $72(15.2)$ & $403(84.8)$ & $475(51,5)$ & 0.001 \\
\hline Engineering Faculty & $173(38.6)$ & $275(61.4)$ & $448(48.5)$ & \\
\hline Age & & & & \\
\hline $18-20$ age & $87(28.8)^{*}$ & $215(71.2)$ & $302(32.7)$ & \\
\hline $21-23$ age & $128(28.0)^{*}$ & $329(72.0)$ & $457(49.5)$ & 0.03 \\
\hline 24 age $\leq$ & $30(18.3)$ & $134(81.7)$ & $164(17.8)$ & \\
\hline Place of Residence & & & & \\
\hline City Center & $206(25.8)$ & $591(74.2)$ & $797(86.3)$ & 0.223 \\
\hline Counties/Village & $39(31.0)$ & $87(69.0)$ & $126(13.7)$ & \\
\hline
\end{tabular}

1: line percentage 2: column percentage ${ }^{*}$ : group creating difference

Table 4: The State of Thinking that Processed Food Allowed to Sell Ministries According

to Socio-demographic Characteristics of the Students Attending the Survey

\section{Table 5}

It was found that the perceptions of students who considered processed foods permitted by the ministry to be unsafe have

\begin{tabular}{|c|c|c|}
\hline & n & \% \\
\hline Inadequate information on additive substances & 251 & 27.2 \\
\hline The lack of confidence to food manufacturers & 373 & 40.4 \\
\hline Lead to allergy & 90 & 9.8 \\
\hline Lead to cancer & 212 & 23 \\
\hline Newspaper and television reports & 65 & 7 \\
\hline
\end{tabular}

Table 5: Distribution of the Students Attending the Survey Causes of Thinking of the Safeguarding of the Permitted Contributions by the Ministry of Food, Agriculture and Livestock 
originated mostly from the lack of confidence to food manufacturers (40,4\%), and the minority (7\%) reported newspaper and television reports as the source of their perceptions (Table 5).

\section{Table 6}

Table 6 presents the distribution of answers students gave to the questions on food additives. The highest percentage of correct responses by the students was noted in questions about the effects of food additives on nutritional value ( $89,4 \%)$, shelf life of the food products $(83,6 \%)$, and definition of food additives $(86,5 \%)$. The lowest percentage of correct responses was noted in questions about the requirement of special permission for food additives added to baby formula and dietary products (9,6\%), inactivation of the vitamins by FAs, requirements about the interference with food absorption (10\%), and classification of FAs as artificial or natural $(22,6 \%)$ (Table 6).

\begin{tabular}{|c|c|c|}
\hline & \multicolumn{2}{|c|}{ Knowing } \\
\hline & $\mathbf{n}$ & $\%$ \\
\hline Definition of food additives & 798 & 86.5 \\
\hline All are harmful to human health. & 404 & 43.8 \\
\hline It can also be artificial or natural. & 209 & 22.6 \\
\hline It is only available in packaged ready-made foods. & 232 & 25.1 \\
\hline Your pills will be healthier if not used. & 724 & 78.4 \\
\hline There is sufficient scientific work in this regard. & 99 & 64.9 \\
\hline E-coded additives are not harmful to health. & 636 & 68.9 \\
\hline Vitamins should not destroy, should not reduce the absorption of nutrients & 92 & 10 \\
\hline The requirement of special permission for food additives added to baby formula and dietary products & 89 & 9.6 \\
\hline There are legal regulations for use in our country & 466 & 50.5 \\
\hline Protectors (antioxidants) are food additives & 691 & 74.9 \\
\hline The food additive is the person who improves the structure, preparation and cooking & 496 & 53.7 \\
\hline Aroma developers are food additives & 707 & 76.6 \\
\hline Nutritional value of the protectives and developers are food additives & 557 & 60.3 \\
\hline Artificial sweeteners are food additives & 755 & 81.8 \\
\hline Flavor enhancers are food additives & 669 & 72.5 \\
\hline Rich developers are food additives & 727 & 78.8 \\
\hline Besine daha iyi tat ve lezzet katmak için kullanılır. & 300 & 32.5 \\
\hline Shelf life of the food products. & 772 & 83.6 \\
\hline It used to add better taste and flavor to food & 311 & 33.7 \\
\hline Does not increase nutritional value & 825 & 89.4 \\
\hline
\end{tabular}

Table 6: Distribution of Responses of the Participants to the Survey Questionnaire

Table 7

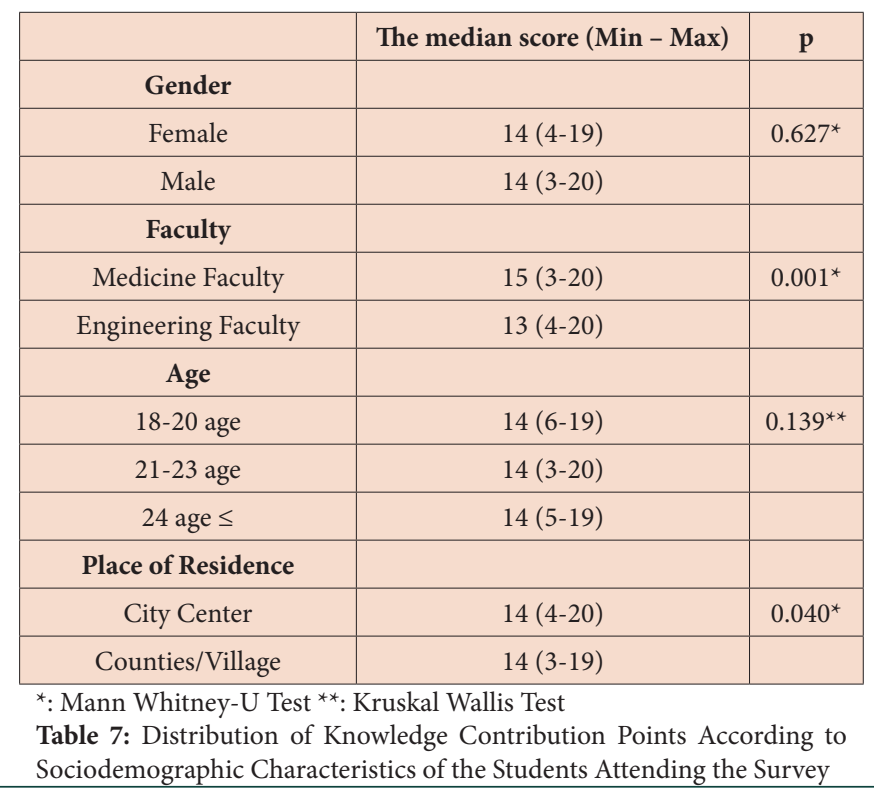


Table 7 presents the food additives knowledge scores of students according with their sociodemographic characteristics. The median knowledge score was 14 (4-19) in females and the median knowledge score was 14 (3-20) in male students ( $p>0.05)$. The mean knowledge score was 15 (3-20) in medical students and 13 (4-20) in engineering students, and the difference was statistically significant $(\mathrm{p}<0.05)$. The median knowledge score was $14(6-19)$ in the $18-20$ age group, 14 (3-20) in the 21-23 age group, and 14 (5-19) in students aged above 24 years $(\mathrm{p}>0.05)$. The median knowledge score was 14 (4-20) in students residing in the city center and 14 (3-19) in students residing in counties and villages, and students residing in the city center achieved significantly higher knowledge scores $(\mathrm{p}<0.05)$ (Table 7$)$.

\section{Discussion}

In line with the technological developments, the requirement for the improvement of food preservation methods and the need to provide the consumer with a better perception about the quality of food have shaped historical development of food additives (FA). The importance of FAs with respect to public health stems from the fact that some of these substances that are authorized by the responsible organizations do not cause any health hazards, whereas some of them pose significant risks in case they are taken in a constant basis. For example, in one study, hyperactivity behaviors increased in children receiving food additives [15]. Research on the health hazards caused by food additives has not been conducted due to the variety and extensive use of these substances, as well as their lifelong absorption even in small quantities [16]. The fact that there are more potential hazards related to FAs in societies where manufacturers and consumers are not conscious increase the significance of consumer's awareness on food additives.

In the present study, 92,2\% of medical students and $80,4 \%$ of engineering students were aware of the definition of food additives $(\mathrm{p}<0.05)$, whereas $85 \%$ of female students and $87,7 \%$ of male students were aware of the definition of food additives $(\mathrm{p}>0.05)$. Among the study subjects, preservatives, artificial sweeteners and flavor enhancers were the most widely known food additives. The results of different studies conducted in Korea are also in line with the findings of the present study $[9,17]$. It is considered that a significant proportion of students being aware of the definition of food additives may be related to the educational level of the studied sample.

The study present found that the most commonly consumed processed foods were packaged cakes, cookies and chocolate, packaged milk and dairy products, chicken and chicken products, whereas the least commonly consumed processed foods were canned goods, salami, pastrami and Turkish sausage. It was also demonstrated that almost half of the students consumed processed foods daily, 32,8\% consumed them 2-3 times a week, 11,2\% consumed them once a week, whereas 1,4\% never consumed processed foods. In line with the findings of the present study, similar studies also demonstrated that the most commonly consumed processed foods were dairy products, and that the most commonly consumed processed foods were snacks $[9,18,19]$. Contrary to our study, a study conducted in Korea reported that the most commonly consumed processed foods were ready to eat products such as ham and sausages. Similar to the present study, with respect to the frequency of consuming processed foods, it was found that $30 \%$ of the participants consumed processed products 2-3 times a week [9]. The results may stem from the fact that participants of the study consumed snacks frequently as they are easily accessible. In addition, in a study on food safety in Turkey, only 5, 5\% of the products with label information were reported to have food additive information [20].This result suggests that the label information may be effective at the consumption rate.

$29,8 \%$ of the female students, $23,5 \%$ of the male students, $25,8 \%$ of the students residing in the city center, and $31 \%$ of the students residing in counties and villages perceived processed foods permitted by the Ministry of Food, Agriculture and Livestock to be safe ( $\mathrm{p}>0.05) .15 .2 \%$ of medical students and $38,6 \%$ of engineering students perceived FAs to be safe $(\mathrm{p}<0.05)$. In a similar study conducted in Korea, $76 \%$ of the participants perceived that the food additives permitted by the government were unsafe, as they thought that the research on food safety is insufficient [9]. Another research, which has been made in China, is reported Participants with higher education had more doubt about additives while those with lower education tended to have more faith in the national or international standards [21]. In the present study, it was found that the students perceived processed foods permitted by the ministry to be unsafe mainly because they did not have confidence in food manufacturers (40,7\%), and newspaper and television reports had minor impact on their perception (7\%). In the Korean example, one fourth of the participants stated that they perceived FAs to be unsafe because they did not have confidence in the food manufacturers, whereas $13 \%$ stated that their perceptions have stemmed from newspaper and television reports. It was also reported that the possible reason regarding the participants' concerns over food additives were negative information they receive from the mass media [9]. In another study conducted in Turkey, consumers found the food additives to be unsafe due to their belief in the negative effect of FAs on health [22]. A study that investigated consumer opinion demonstrated that most of the consumers were unaware of the advantages and disadvantages of food additives, and that education is required in this respect [23]. The results show that food manufacturers are insufficient in providing confidence to the consumers; and moreover, visual and printed media are insufficient in informing consumers.

The median knowledge score of medical students was 15 (3-20), whereas the median knowledge score of engineering students was 13 (4-20); and the median score of students residing in the city center was 14 (4-20), and the median score of students residing in counties and villages was $14(3-19)(\mathrm{p}<0.05)$. When the responses of the students to questions regarding food additives are 
evaluated, the highest percentage of correct responses was noted in questions about the effects of food additives on nutritional value (89.4\%), shelf life of the food products (83.6\%), and definition of food additives (86.5\%). On the other hand, the lowest percentage of correct responses was noted in questions about the requirement of special permission for food additives added to baby formula and dietary products (9.6\%), inactivation of the vitamins by FAs, and the requirement that food additives should not interfere with food absorption (10\%). We also found similar results in different studies in the literature [9,24]. On the otherhand a research, which has been made in medical doctors, reported that the level of knowledge on food additives was not found high [25]. This result is thought to be due to the fact that the mean age of the research group was larger than our study. It may be argued that higher scores medical students obtained from the questions on FAs may be due to their education in general, and the fact that they are more informed and concerned about factors effecting human health.

\section{Conclusion}

The present study have demonstrated that the rate of the participants who knew the definition of food additives as well as those who perceived food additives to be unsafe were high. Although the knowledge levels on FAs of the students were high in general, it was observed that the frequency of food consumed daily was high also. In conclusion, more detailed research on FAs as well as receiving reliable information via efficient implementations is required to transform knowledge into practice.

\section{References}

1. Food and agriculture organization (2016) Codex General Standard For The Labellıng Of Food Additıves When Sold As Such, USA.

2. Resmigazete (2013) Official Gazette numbered 28693 of Turkey, Turkey.

3.European Food Safety Authority (2016) Food additives, Europe.

4. Birch GG, Campbell-Platt G (1993) Consumer perceptions of food safety and their impact on food choice In: Food safety-the challenge ahead, Andover : Intercept, UK.

5. Altug T, Elmaci Y (1995) A consumer survey on food additives. Dev Food Sci 37: 705-19.

6. Altug T (2001) Food Additivies. Meta Edition, İzmir, Turkey.

7. Bosi Bagcı AT (2015) Food Additives and Food Control (3th end) In: Guler C, Akın L, editors, Ankara.

8. Yurttagul M, Ayaz A (2008) Additivies: Wrongs and rights. Hacettepe University-Faculty Health Sci, Dep Nutr Diet, Ankara.

9. Shim SM, Seo SH, Lee Y, Moon GI, Kim MS et. al. (2011) Consumers' knowledge and safety perceptions of food additives: Evaluation on the effectiveness of transmitting information on preservatives. Food Control 22: 1054-60.

10. Ritson C, Mai L (1998) The economics of food safety. Nutr Food Sci 98: 253-9.

11. Joint FAO/WHO (2003) Codex Alimentarius Commission, Joint FAO/WHO Food Standards Programme, and World Health Organization, Codex Alimentarius, Rome.

12. Mortensen A, Aguilar F, Crebelli R, Di Domenico A, Dusemund B, et al. (2017) Approach followed for the refined exposure assessment as part of the safety assessment of food additives under reevaluation. EFSA J 15: e05042.

13. Gioia LC, Ganancio JR, Steel CJ (2017) Food Additives and Processing Aids used in Breadmaking. In Desiree Nedra Karunaratne, editör, Food Additives, Sri Lanka InTech.

14. Carocho M, Morales P, Ferreira IC (2015) Natural food additives: Quo vadis?. Trends in Food Sci Technol 45: $284-95$.

15. McCann D, Barrett A, Cooper A, Crumpler D, Dalen L, et al, (2007) Food additives and hyperactive behaviour in 3-year-old and 8/9-year-old children in The community: a randomised, double-blinded, placebo-controlled trial. The Lancet 370: 1560-67.

16. Saklanil İ (1985) Food Additives and the Ingredients, Ankara.

17. Korea Food and Drug Administration (2008) Dietary intake of food additive by Korean population,.

18. Lee CH, Cho YH, Park KH (2006) Assessment of estimated daily intake of nitrite by average consumption of processed foods in Korea. Food Control 17: 950-6.

19. Lee JS (2009) Perception on nutrition labeling of the processed food among elementary school teachers in Busan. Korean J Community Nutr 14: 430-40.

20. Gunes FE, Aktac S, Korkmaz BI (2014) Tüketicilerin Gıda Etiketlerine Yönelik Tutum ve Davranışları. Akademik Gıda 12: $30-7$.

21. Wu L, Zhong Y, Shan L, Qin W (2013) Public risk perception of food additives and food scares. The case in Suzhou, China. Appetite 70: 90-8.

22. Nurhan U (2007) Consumer food safety knowledge and practices in the home in Turkey. Food Control 18: 45-51.

23. Woods M (1987) Food additives; the law, the consumer and communication. J Food Sci Technol 1: 232-4.

24. Jung HY, Nan LH (2009) Recognition of food additives of high School students in Gwangju. J Korean Home Econ Assoc 21: 1-17.

25. Gultekin F, Savas HB, Ceyhan MB, Atay MB, Cetinkaya N, et al. (2014) Medical Doctors' Perceptions of Food Additives. Int J Basic Clin Med 2: 118-22. 


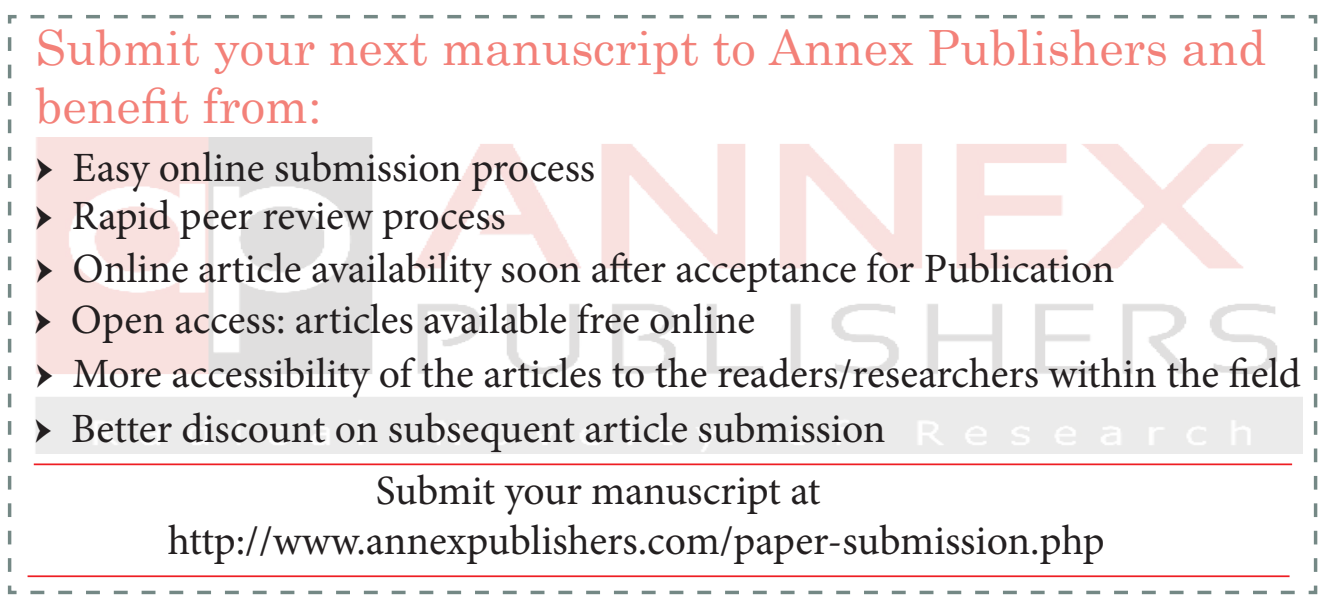

